\title{
Towards Development of Web-Based Assessment System Based on Semantic Web Technology
}

\author{
$\underline{\text { doi:10.3991/ijim.v5i1.1439 }}$ \\ Hosam F. El-Sofany ${ }^{1}$, and Samir A. El-Seoud ${ }^{2}$ \\ ${ }^{1}$ Cairo Higher Institute for Engineering, Computer Science, and Management, Cairo, Egypt \\ ${ }^{2}$ Technische Universität Darmstadt, Darmstadt, Germany
}

\begin{abstract}
The assessment process in an educational system is an important and primordial part of its success to assure the correct way of knowledge transmission and to ensure that students are working correctly and succeed to acquire the needed knowledge. In this study, we aim to include Semantic Web technologies in the E-learning process, as new components. We use Semantic Web (SW) to: 1) support the evaluation of open questions in e-learning courses, 2) support the creation of questions and exams automatically, 3) support the evaluation of exams created by the system. These components should allow for measuring academic performance, providing feedback mechanisms, and improving participative and collaborative ideas. Our goal is to use Semantic Web and Wireless technologies to design and implement the assessment system that allows the students, to take: web-based tutorials, quizzes, free exercises, and exams, to download: course reviews, previous exams and their model answers, to access the system through the Mobile and take quick quizzes and exercises. The system facilitates generation of automatic, balanced, and different exam sheets that contain different types of questions covering the entire curriculum, and display gradually from easiness to difficulty. The system provides the teachers and administrators with several services such as: store different types of questions, generate exams with specific criteria, and upload course assignments, exams, and reviews.
\end{abstract}

Index Terms-E-learning, M-learning, Semantic Web, Educational Systems, Evaluation Systems, Interactive Applications.

\section{INTRODUCTION}

Traditional assessment modes in crowded classrooms can be a serious load on the instructors $[13,14]$. Considering roles of the instructors in digital age, use of internet and even wireless technologies in the assessment can be very useful starting point for the instructors in order to be successful in integrating new technologies to the courses. Moreover, this integration process will support their professional career development.

Rouet et al. in [15] conducted a study to investigate the impact of web-based and paper based delivery of quizzes on students' performance and perceived satisfaction. They found that students who studied with printed documents and undertook paper based quiz were superior to the students who studied with web documents and took webbased quiz. Although the students expressed preference on the paper materials and paper based quiz they appreciated the availability of the course web site. As authors suggested while integrating web technologies into assessment phase of the instruction, ease of use and legibility of the tests should be taken into considerations. Besides accessibility of the online content and test of the courses are important factor to support students anytime, anywhere access to the instruction.

In recent years, most universities recognized the educational excellence of the wireless campus. This is a great opportunity for the students to access information more easily at any area of the campus using their laptops. In addition, with the promotion of Palm, Pocket PC and Mobile Phones as learning media, the number of practices which deals with integrating such devices into instruction has increased in the universities. Thus, the students can reach the course scores, discussion forums, information systems and tests by using mobile phones and PDA devices whenever and wherever they want.

Seppälä and Alamäki in [16] conducted a study on comparing the effectiveness of face-to-face, internet and mobile based instruction. As a result of their study, they suggested that innovative internet and mobile solutions can be useful for academic teaching because of providing possibilities for open teaching.

Use of WAP or SMS based tests through PDA, PALM, mobile phone or computer in higher education has been promoted due to the fact that they support the learning process of the students, offer exercise media and provide the opportunity to test the expected learning level achieved [17-19]. However, as stated by Homan and Wood [20], the cost of such services for the students should be decreased so that these new learning media can be widely used. Homan and Wood analyzed the achievement level and views of the students on the paper based and mobile based tests in internet based wireless and traditional classrooms. They found that there was no significant difference between students' achievement level and the students had positive views about the wireless test conducted on PDA, however the students stated that they wanted to use the infrastructural opportunities of the university, instead of their own devices.

The results of the most researches in the literature have focused on the students' achievement level in web or paper based tests in the university level education. This study aims to determine and measure the effects of Webbased and Mobile-based assessments on the achievement 
levels, performance and perceptions of the students in internet-assisted courses in the Qatari schools.

The aim of this study is not to provide all the features contained in Course Management Systems such as Moodle or Blackboard, but to providing the basic support for carrying out the assessment processes.

The main objectives of this research project are:

1) Design and implement the web-based assessment system, using Semantic Web (SW), and Mobile technologies. The project allows the students:

1-1 To take: web-based tutorials, quizzes, free exercises, and exams (monthly, midterms and finals).

1-2 To download: course reviews, previous exams and their model answers.

1-3 To access the system through wireless devices (such as, Mobile phone, PDA- Personal Digital Assistants, and Tablet PC) and take quick quizzes and exercises.

2) Develop new algorithms to improve the assessment process in the schools:

To improve the assessment process in the schools, by developing new algorithms and techniques to generate balanced; exam sheets (monthly, midterms and finals), quizzes, and exercises, that containing different types of questions, covering the entire curriculum, and displaying gradually from easiness to difficulty. The exam sheets produced by the system take into account the different levels of the students from excellent, good, to fair, and avoids any mistakes of language and non-clear terminologies.

3) Provide the teachers and the administrators with several management services. In addition of the traditional admin services such as: login, change password, add, update, delete the basic data for the system (levels, subjects in each level, school, classes, teachers and students data), the project provided the following services to the teachers and administrators:

3-1 Store different types of questions: multiple choices, matching, filling in the blanks, true or false, parallel lists, etc.

3-2 Generate exam sheets (monthly, midterms and finals) with specific criteria: the number of questions, total score, chapters limit, lessons limit, and time limit.

3-3 Upload course assignments, previous exams, and their model answers.

3-4 Make sure that students have submitted their assignments, quizzes, and homework.

4) Determine and measure the effects of Web-based and Mobile-based assessments on the achievement levels, performance and perceptions of the students in internetassisted courses in the schools:

To assist the educational system for transferring from traditional learning to computer-based and mobile-based learning, by allowing students and instructors to participate in remote learning communities using personal computers and mobiles at home or at school.

\section{ANALYSIS AND DESIGN METHODS}

We build first the general architecture of the system, set the graphical user interface and design the structure of the database that stores the required data and information. In order to achieve our goals we defined the following tasks:

\section{A. System Analysis}

The analysis phase is the main phase in which the assessment system requirements are identified in more details. The goal of this phase in the system development is to represent the system goals into defined functions and operations of the intended applications. The assessment system requirements are documented in a complementary set of artifacts (flowcharts, use case diagrams, system sequence diagrams, ...). Each artifact provides a different perspective of the system under design and contains distinct requirements. The combination of these perspectives establishes the tasks that are to be accomplished by the system.

- Information Gathering Techniques: By assisting of some specialist employees from the SEC (Supreme Education Council), all the system materials are checked to match the SEC curriculum. The following are some information gathering techniques that used in the assessment system analysis.

- Interviews: The most common technique for gathering requirements is to sit down with the clients (teachers, students, parents, and school administration) and ask them what they need. Our discussion would help us plan out ahead of time, based on the type of requirements that we are looking for.

- Prototyping: We use this technique for gathering requirements. In this approach, we gather preliminary data and requirements that we use to build the initial version of the system.

- $\quad$ UML (Universal Modeling Language) use-cases is used also in the analysis of the assessment system as a model tool, in which the functional requirements are extracted and described along with a scenario of the flow of events.

The system requirements are classified in two types: functional and non-functional requirements.

- Functional requirements: The assessment system allows different types of users to interact with the system according to given privileges. There are three main users of the system: administrator, teacher, and student, as shown in Figure 1. The system provides the following applications (services) to each user:

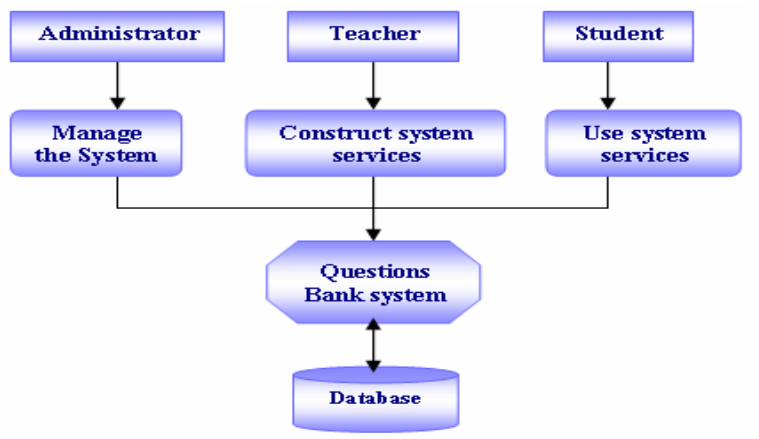

Figure 1. The three main users of the system 
1. The administrator application: This application provides the school administrator with simple tools to manage the information of the assessment system. The following are some features provided by the administrator application:

- Activate/inactivate the system.

- Import and export the system' database

- Send automatic email immediately containing the new password whenever the user changes his/her password.

- Administer the basic data and information of the system: levels, subjects (or courses) teachers, and students.

2. The teacher application: This application provides the teachers with various tools to construct the system services. The following are some features provided by the teacher application:

- Change account password

- Manage (add, update, delete and display) all the system services (tutorials, reviews, exam questions, quizzes, previous exams, and model answers).

- Print his/her exam sheets (monthly, midterms and finals) with specific criteria: the number of questions, total score, chapters limit, lessons limit, and time limit.

- As mentioned before, the system helps the teachers to print automatic, balanced, and different exam sheets that contain different types of questions covering the entire curriculum, and display gradually from easiness to difficulty.

3. The student application: This application provides the students with interactive tools to use the services of the system. The following are some features provided by the student application:

- Change account password

- Download assignments, revision documents, previous exams and their model answers, and other files that are uploaded by the teachers.

- Take web-based tutorials, quizzes, free exercises, exams (monthly, midterms and finals).

- Access the assessment system through wireless devices (such as, Mobile phone, PDA and Tablet PC) and take quick quizzes and exercises.

- Non-functional requirements: In this part, we have verified and proved the system' aspects and interfaces that are not directly related to the functional behavior, such as: usability, reliability, supportability, performance, and security.

- Hardware and software resource: We have used some software during our first prototype of the system development such as: Windows XP professional, Windows Server O/S, Microsoft office Excel, Microsoft Word, SQL Server database system, MS Visual Studio.Net, and Photo Shop.

To extend our research work, by using Semantic Web and Mobile technologies, we used other new languages and tools including: XML- eXtensible Markup Language, XML Schemas, RDF- Resource Definition Framework, RDF Schemas, OWL- Web Ontology Language, and Java 2ME.

\section{B. System Design}

Any successful web-based system should have an easy to use graphical user interface (GUI) that facilitates its use and flexibility. Thus the proposed system should possess an attractive GUI that is suitable to the potential users. The interface should be tested by its users and updated whenever necessary.

- System architecture: The assessment system interface is entirely web-based, and doesn't necessitate any technical skills from the potential users. The system is divided into three applications, called administrator, teacher, and student application. As shown in Figure 2, the system is appropriate for on-campus teaching, with access to the Internet, or off-campus teaching using the local network.

- Database design: Database is an important component in our system. We have used Microsoft SQL Server database as a database management system (DBMS). The DBMS stores the subjects in each school level, the tutorials, the reviews, the previous examinations, the exams questions, the quizzes, the student grades, and the basic information of the administrators, teachers, and students. We have chosen the entity-relationship model to represent the database design. In [6] we introduced the basic entityrelationship diagram, that contains the main entities (tables) used for creating the system database.

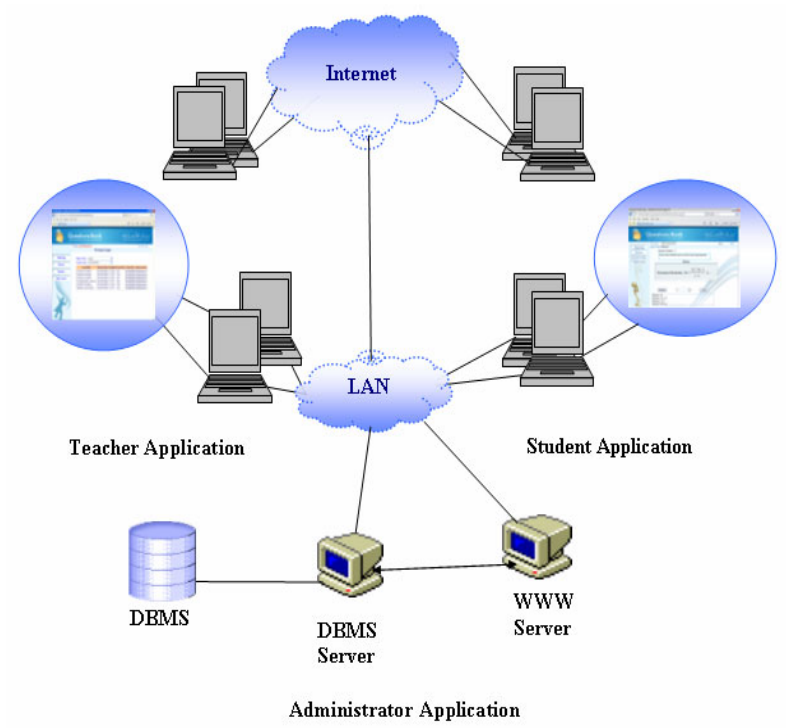

Figure 2. System architecture

- Using Semantic Web as a new methodology for Elearning research :

The Semantic Web appears as a promising technology for implementing E-learning. The Semantic Web constitutes an environment in which human and machine agents will communicate on a semantic basis [8]. One of its primary characteristics, viz. shared understanding, is based on ontologies as its key backbone. Ontologies enable the organization of learning materials around small pieces of semantically annotated learning objects [9]. Items can be easily organized into customized learning courses and delivered on demand to the user, according to her/his profile and business needs. 
Semantic Web architecture: The term "Semantic Web" encompasses efforts to build a new WWW architecture that enhances content with formal semantics. That means, content is made suitable for machine consumption, as opposed to content that is only intended for human consumption. This will enable automated agents to reason about Web content, and produce an intelligent response to unforeseen situations.

"Expressing meaning" is the main task of the Semantic Web. In order to achieve that objective several layers of representational structures are needed. They are presented in the Figure 3, among which the following layers are the basic ones [8]:

- The XML layer, which represents the structure of data,

- The RDF layer, which represents the meaning of data,

- The Ontology layer, which represents the formal common agreement about meaning of data,

- The Logic layer, which enables intelligent reasoning with meaningful data.

The important property of the Semantic Web architecture (i.e., common-shared-meaning and machineprocessable metadata), enabled by a set of suitable agents, establishes a powerful approach to satisfy the E-Learning requirements. The process is based on semantic querying and navigation through learning materials, enabled by the ontological background. The Semantic Web can be exploited as a very suitable platform for implementing an Elearning system, because it provides all means for $\mathrm{E}$ learning: ontology development, ontology-based annotation of learning materials, their composition in learning courses and active delivery of the learning materials through E-learning portals. Table 1, shows the suggested advantages to the possibility of using the Semantic Web for realizing the proposed E-learning requirements.

\section{- The proposed Semantic Web framework for as- sessment system:}

Our basic Semantic Web framework illustrated in Figure 4, provides the student with different types of assessment services. In this research study we focus on the implementation of these services that allows the students to take: web-based tutorials, quizzes, free exercises, exams (monthly, midterm, and final), to download: course reviews, previous exams and their model answers, to access the system through the Mobile and take quick quizzes and exercises. On the other hand, the system allows the teacher to store different types of questions, to check the contents of the site and update it regularly, to generate exams with specific criteria, to make sure that students have submitted their assignments, and to make students up to date by posting different announcements.

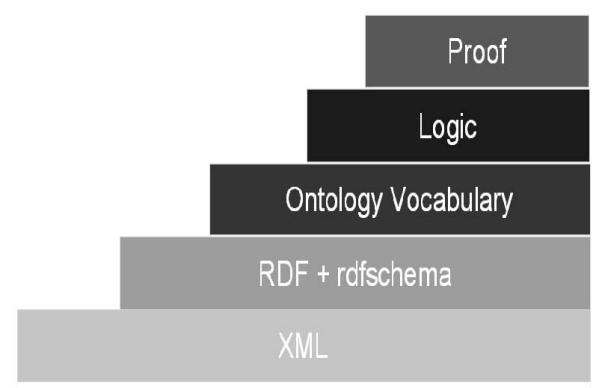

Figure 3. Layers of the Semantic Web
TABLE I.

AdVANTAges of Using SeMANTIC Web AS A TECHNOLOgy For ELEARNING

\begin{tabular}{|c|c|c|}
\hline \multicolumn{2}{|c|}{ E-leaming Semantic Web } & \multirow{2}{*}{\begin{tabular}{|l|} 
Requirements \\
Delivery
\end{tabular}} \\
\hline $\begin{array}{l}\text { Knowledge items (leaming materials) are distributed } \\
\text { on the web, but they are linked to commonly ageed } \\
\text { ontologies. This enables construction of a user- } \\
\text { specific course, by semantic querying for topics of } \\
\text { interest. }\end{array}$ & Pull - student detemines agenda & \\
\hline $\begin{array}{l}\text { Software agents on the Semantic Web may use a } \\
\text { commonly agreed service language, which enables } \\
\text { co-ordination between agents and proactive delivery } \\
\text { of leaming materials in the context of actual } \\
\text { problems. The vision is that each user has his own } \\
\text { personalized agent that communicates with other } \\
\text { agents. }\end{array}$ & $\begin{array}{l}\text { Reactionary - responds to } \\
\text { problem at hand }\end{array}$ & Responsiveness \\
\hline $\begin{array}{l}\text { User can describe the situation at hand (goal of } \\
\text { leaming. previous knowledge,...) and perform } \\
\text { semantic querying for the suitable leaming matenal } \\
\text { The user profile is also accounted for. Access to } \\
\text { knowledge can be expanded by semantically defined } \\
\text { navigation. }\end{array}$ & $\begin{array}{l}\text { Non-linear - allows direct access } \\
\text { to knowledge in whatever } \\
\text { sequence makes sense to the } \\
\text { situation at hand }\end{array}$ & Access \\
\hline $\begin{array}{l}\text { The Semantic Web offers the potential to become an } \\
\text { integration platform for all business processes in an } \\
\text { organization, including leaming activities. }\end{array}$ & $\begin{array}{l}\text { Symmetric - leaming occurs as } \\
\text { an integrated activity }\end{array}$ & Symmetry \\
\hline $\begin{array}{l}\text { Active delivery of information (based onpersonalized } \\
\text { agents) creates a dynamic leaming envirorment that is } \\
\text { integrated in the business processes. }\end{array}$ & $\begin{array}{l}\text { Continuous - leaming nums in } \\
\text { parallel to business tasks and } \\
\text { never stops }\end{array}$ & Modality \\
\hline $\begin{array}{l}\text { The Semantic Web will be as decentralized as } \\
\text { possible. This enables an effective co-operative } \\
\text { content management. }\end{array}$ & $\begin{array}{l}\text { Distributed-Cortent comes } \\
\text { from the interaction of the } \\
\text { participarts and the educators }\end{array}$ & Authonity \\
\hline $\begin{array}{l}\text { A user (using its personalized agent) searches for } \\
\text { leaming material customized for her his needs. The } \\
\text { ontology is the link between user needs and } \\
\text { characteristics of the leaming material. }\end{array}$ & $\begin{array}{l}\text { Personalized-content is } \\
\text { detemined by the individual } \\
\text { user's needs and ams to satisfy } \\
\text { the needs of every user }\end{array}$ & Personalization \\
\hline $\begin{array}{l}\text { The Semantic Web enables the use of distributed } \\
\text { knowledge provided in various forms, enabled by } \\
\text { semantically annotation of content. Distubutednature } \\
\text { of the Semantic Web enables continuous } \\
\text { improvement of leaming materials. }\end{array}$ & $\begin{array}{l}\text { Dynamic - content changes } \\
\text { constartly through user input, } \\
\text { experiences, new practices, } \\
\text { busimess rules and heuristics }\end{array}$ & Adaptively \\
\hline
\end{tabular}

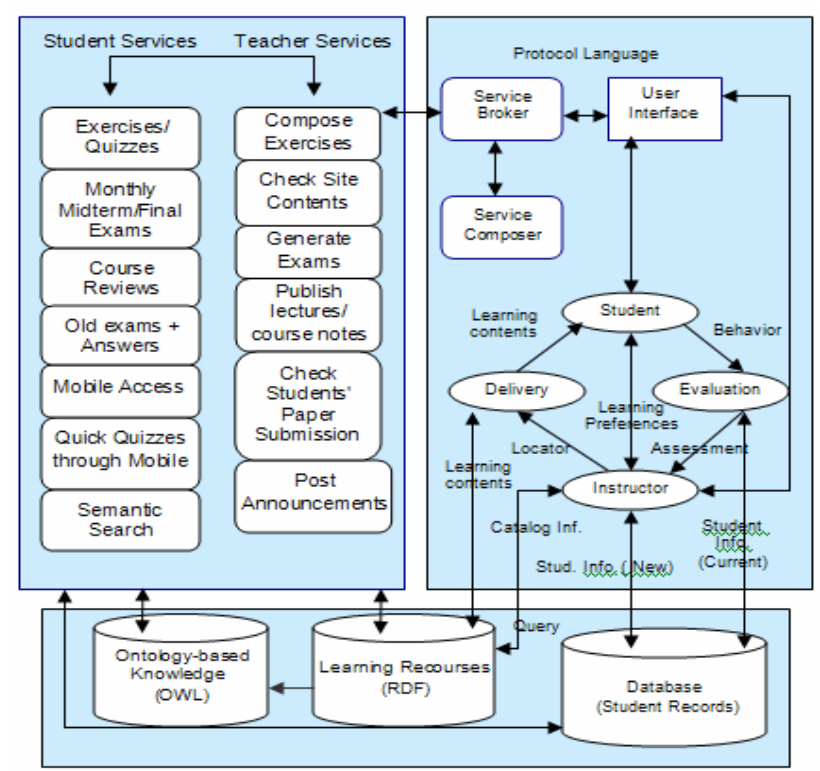

Figure 4. Basic Semantic Web framework for assessment system

\section{- Using Mobile technology as a new stage for E- learning research:}

M-learning means the provision of education and training materials and courses on wireless devices: portable computers, PDA's, mobile telephones and Tablet PC. Our learning system has functions to enter and to organize the learning objects in the database and to make them available for students and teachers using the learning management systems (LMS) portals in which the learning process and its activities have been structured [4,5]. Most of the elearning student applications have been made available for users of mobile computers, the laptop and the PDA. The learning object management systems are now compatible for all kind of user devices, the conventional desktop PC as well as the mobile devices laptop, PDA and mobile 
telephone. As mentioned before, one of the main objectives of this study is to use mobile technology to provide schools with M-learning system that help in student assessment process.

- The advantages: The advantages of mobile learning refer mostly to the mobile user: a great flexibility, an improved learning schedule is possible, increased productivity during dead moments and just in time learning.

- Difficulties and limitations: Nevertheless they have very small screens, limited memory capacity and the large diversity of mobile devices obstruct a good learning experience. In the educational field we notice that the learning materials must answer to specific conditions. We will have to get around the technical restrictions so we can create a good learning experience. The usage of video, audio, clear interfaces and divided courses must contribute to this. Furthermore we will have to adapt the content to the needs of the mobile user. Because the user has a fragmentized time schedule, we will have to be sure that the learning object (quiz, exercise, ...) are not to long. Dividing the knowledge in smaller modules offers a solution.

\section{Exam Generation Algorithms}

As mentioned before, one of the main objectives of the proposed study is to improve the assessment process in the schools, by developing new algorithms and techniques to generate balanced; exam sheets, quizzes, and exercises, that containing different types of questions, covering the entire curriculum, and displaying gradually from easiness to difficulty. One of these innovative and intelligent algorithms is the "ManageQuestion" algorithm that used for managing the difficulty of the exam (quiz and exercise) questions. The algorithm uses the difficulty attribute set by the user as input parameter. The teachers set the difficulty levels of their questions at creation phase using a numbering system. The value assigned to a specific question identifies how difficult (or easy) it would be for a student to reply correctly to the question. Our algorithm can generate automatically different exams with different levels of difficulties. Obviously, teachers are not always as accurate as would be desirable in estimating the difficulty of a question (as they don't know the exact level of the students using the system) our algorithm can update the difficulty and the easiness of the questions based on the responses given by the students. The algorithm has the ability to detect the difficulty/easiness of a question based on students reply and adjust the difficulty value accordingly. As a result, some of the feedbacks of the students in a given course are used to adjust the level of the questions. The following are the some functions of our algorithm:

- Get_Difficulty(): This method determines the difficulty of a specific question.

- Calc_Margn(): This method calculates the lower and the upper bounds of error percentage in the students' responses.

- Calc_Error(): This method calculates the percentage of wrong responses to a question, as a ratio between errors and a constant value named Max_Num_Access. The involved variables are reset after each difficulty evaluation.
- Mark Ques(): This method activates a Boolean field in the register of a question if the difficulty level reaches the thresholds.

\section{Algorithm: ManageQuestion(difficulty):}

Access random question from the "questions" database table:

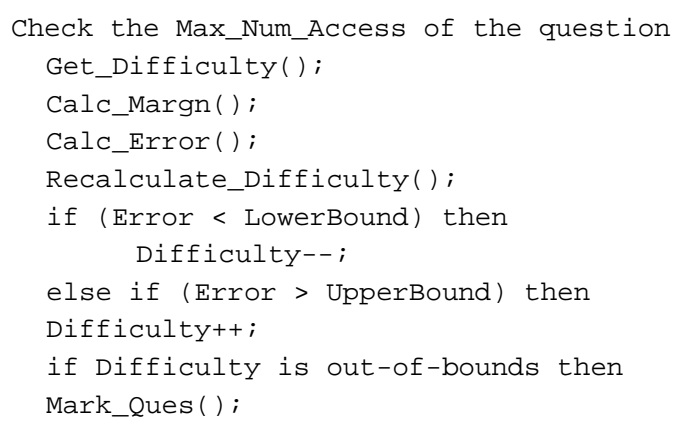

Four difficulty degrees have been considered rangy from level one to level four. If a question has a value higher than four, it could be too difficult or it could be ambiguous. Similarly, if a question has a value of 0 , the question could be too easy, or too obvious, and nearly all the students can answer it correctly. The questions that are out of bounds are marked, so they cannot be used for any exam (or quiz), and the teachers must update them. Table 2 shows the upper and lower bounds for determining the difficulty of the questions $[1,2]$.

TABLE II.

QUESTIONS LEVELS

\begin{tabular}{|c|c|c|}
\hline Difficulty & Lower bound (\%) & Upper Bound (\%) \\
\hline 1 & 10 & 30 \\
\hline 2 & 30 & 50 \\
\hline 3 & 50 & 70 \\
\hline 4 & 70 & 90 \\
\hline
\end{tabular}

\section{SYSTEM IMPLEMENTATION}

Database implementation: The current database is designed to have the following main tables: Level, Subject, ReviewFile, Quiz, ExamFiles, Questions, StudentScore, Student, Teacher, and Administrator. During the development of the system, data for the testing of different functionalities was needed to be imported into the database tables. The tables are filled by importing the data from an MS Excel sheet that contains the basic data from the school's database or during the run time of the system.

Ontology implementation: As mentioned in our proposed Semantic Web model, Figure 4, the ontological knowledge is added to the learning resources as a resource for contextual learning, and it searched by means of queries. The student's performance is measured by the evaluation component, and the result is stored in the student records database. The data in the database can be used by the instructor component to locate a new content. Searching learning resources and sequencing a course can be done using a knowledge base of learning resources and a delivery component. To implement the knowledge base, first of all, the leaning resources have to be described by means of metadata. The metadata consists of the contextual knowledge of the learning resources, i.e., ontology in 
our model. It contains the general representation of the structural knowledge on specific domains, such as Science, Mathematics, English, and so on. The ontology can be used for adaptive learning to retrieve the context of a course and to structure the contents. Also the metadata actually consists of the framing description of each learning object of a subject, i.e., the modularized content, which is linked to the concept of the ontology. For instructors to be able to sequence courses and create exercises adaptively, the suitability of different approaches has to be analyzed based on the relationships between the resources and their descriptions.

System requirements implementation: To prove the functionality of the assessment system, we have implemented several web-based applications as components of the system. The assessment system is divided into three sub-systems: the administrator, the teacher, and the student sub-system. Figure 5, shows a snapshot of our system interface that developed as a grant project [6].

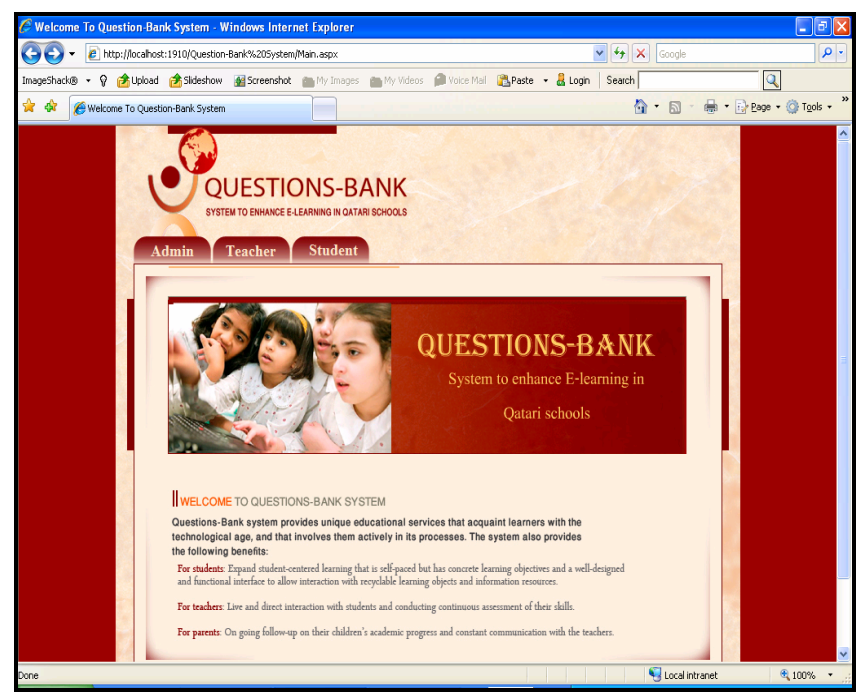

Figure 5. The assessment sub-systems [6]

i. The administrator sub-system: This sub-system provides the school administrator with web-based services to manage the information of the assessment system. the following services are available in the administrator subsystem:

- Login: username and password is the most common authentication method.

- System management: provides the school administrator with web-based services to add (update, or delete) the basic data needed for the other two subsystems, such as: levels, subjects in each level, school, classes, teachers and students data

- Change password: The system provides the user to change his/her account password.

ii. The teacher sub-system: This sub-system provides the teacher with web-based tools to manage the information of the assessment system. In addition to the login, and change password, the following services are available in the teacher sub-system:

- Tutorials administration: Teacher uses this service to upload the MS Word, PP presentation, video, etc. files that contain the tutorials for each subject. Also teacher can delete specific tutorial (s) from the database and can display the stored tutorials.

- Reviews administration: Teacher uses this service to upload (add) the MS Word, PP presentation, video, etc. files that contain the reviews for each subject. Also teacher can delete specific review(s) from the database and can display the stored reviews. The teacher can store the following data for each review: level name, subject name, review title, review date, review file, and the review answer file (if exist).

- Previous exams administration: Teacher uses this services to upload (add) the previous exams and their model answers for each subject. Also teacher can delete specific exam(s) from the database and can display the stored exams. The teacher can store the following data for each previous exam: level name, subject name, exam type (midterm, final), exam title, exam date, exam file, and the exam answer file (if exist).

- Exam administration: Teachers can use this online tool to add, update, and delete questions and answers for their exams (quizzes, and exercises). The questions are inserted into the database dynamically, so new questions can be added during the configuration of exam or quiz. The teacher can store the following data for each exam/quiz: level name, subject name, chapter number, lesson number, quiz title, quiz type (multiple choices, true or false, fill in the blank, ...), question text, question image file, choice1, choice2, choice3, choice4, correct answer, question weight (difficulty), question score, and question explanation.

- Print exam sheets: Teachers can use this on-line tool to print balanced exam sheets (monthly, midterms and finals), quizzes, and exercises, that containing different types of questions, covering the entire curriculum, and displaying gradually from easiness to difficulty. The exam sheets produced by the system take into account the different levels of the students from excellent, good, to fair, and avoids any mistakes of language and non-clear terminologies.

- Mobile quizzes and exercises: Teachers can use this on-line tool to add, update, and delete questions and answers for their Mobile quizzes and exercises.

- Print students' scores: Teacher uses this tool to print the grade reports for the students who took the web-based and mobile-based quizzes and exams created by the system.

iii. The student sub-system: This sub-system allows the student to: 1) download tutorials, reviews, previous exams and their model answers, 2) to take: web-bases exams, quizzes, and free exercises, 3) to take mobile-based quizzes and exercises. In addition to the login, and change password, the following services are available in the student sub-system:

- Download reviews: Student can use this service to download the reviews files for his/her subjects. The student select the subject name, and the teacher name (as input) from the available list of values, the 
system search for the required query, and displays all the stored reviews from the database.

- Download tutorials: Student can use this service to download the tutorials files for his/her subjects.

- Download previous exams: Student can use this service to download previous exams and their model answers for his/her subjects. The student select the subject name, and the teacher name (as input) from the available list of values, the system search for the required query, and displays all the stored exams from the database.

- On-line quiz: After a student login into the system from the student login page, he/she can select the quiz, where the questions will be selected randomly by our algorithm from the database. The quiz will be over either whenever the student finishes it and select the "Finish" button, or whenever a pre-allocated time will be over. The system will calculate the number of correct answers and display the result. Finally, the student score will be saved in the corresponding database for possible tracking. When the student finishes the quiz, a record will be created in the StudentScore table, and stored in the database. Teachers can consult this table to track the activities of their students.

- On-line free exercises: Student can use this service to take free web-based exercises for his/her subjects by setting his/her interested criteria: the number of questions in the exercises, chapter number, lessons limit, font size, and time allowed.

- Wireless quizzes and exercises: Student can use this service to access the system (not just anytime, but anywhere) through wireless devices (such as, Mobile phone, PDA- Personal Digital Assistants, and Tablet PC) and take quick quizzes and exercises.

\section{System Testing AND EVAluation}

Materials and methods: we have used $2 * 3$ factorial design methods in this study to test and to evaluate the assessment system on school site and to get the feedback of students, teachers and parents who are the potential users of the system. Dependent variable of the study is the scores obtain from the students who take the web-based quizzes, exams, tutorials, and free exercises by the system in different months. The students are divided into two groups, including experimental group and control group.

Participants: in the initial test of this study we selected 30 students from preparatory-three level (class 9-A) to form experimental group and 30 students (class 9-B) to form control group. Experimental group took paper based exam, web-based exam and mobile based exam respectively for 3 weeks. Control group took only paper based exam for 3 weeks. Each exam consisted of 10 true-andfalse questions and is scored by 10 points.

Survey: The perceptions of the students in the experimental group who undertook paper based exam, web-based exam and mobile based exam are gathered with the survey. The survey is validated and revised by experts. The survey consisted of 13 questions, 11 of which are 5-point Likert type questions ( $1=$ Strongly Disagree, $2=$ Disagree, 3 = Undecided, $4=$ Agree and $5=$ Strongly Agree) and 2 of which are open ended. These open ended questions are designed to ask students to explain which exam they liked most and which exam they liked least.

Procedure: The initial study conducted on the students from 2 classrooms for 3 weeks. All exams are including true-and-false questions. In the first week, paper based exam is applied to both groups. The scores of paper based exam are announced to the students one week later. In the second week, web-based exam is given to the experimental group, while paper based exam is given to the control group. 10 questions are broadcasted together on one screen in web-based exam. The feedback is given on the next screen to inform students about their answers for each question, the correct answer of the questions and the number of correct and incorrect answers and their scores. In the third week of the study, control group is informed on the scores they received from paper based exam which they took in previous week and they were given paper based exam in the third week. The students in the experimental group are given mobile based exam which are formed of 10 true-and-false questions. The questions in the mobile based exam are displayed sequentially. Before the mobile based exam ended, they have the opportunity to go back to the previous questions and change their answers. Feedback page which are displayed at the end of mobile based exam informed the students about number of correct and incorrect answers and their scores. The students enter the web-based exam and mobile based exam with their student ID numbers and passwords and they have right to use these systems only once. Each exam has 10 true-and-false questions, the numbers of correct answers are calculated as the achievement score and there is no time limitation.

Results: To measure the achievement and student' perceptions in paper based, web-based and mobile based exams, we have applied two-factor ANOVA (Analysis of Variance) for repeated measurements to find out whether there is significant difference between the scores of the students. Table 3 summarizes the ANOVA results, and Table 4 summarizes the means and standard deviations of the answers that computed

TABLE III. THE TWO WAY ANOVA FOR REPEATED MEASURES OF STUDENTS' SCORES IN PAPER, WEB, AND MOBILE BASED TEST.

\begin{tabular}{|l|c|c|c|c|c|}
\hline Source of variation & $\begin{array}{c}\text { Sum of } \\
\text { Square }\end{array}$ & df & $\begin{array}{c}\text { Mean } \\
\text { Square }\end{array}$ & $\mathbf{F}$ & $\mathbf{p}$ \\
\hline Between Groups & 142.290 & 37 & & & \\
\hline $\begin{array}{l}\text { Group (Experimen- } \\
\text { tal/control) }\end{array}$ & .490 & 1 & .50 & .125 & .726 \\
\hline Error & 140.980 & 35 & 3.94 & & \\
\hline Within Group & 167.989 & 77.20 & & & 0 \\
\hline $\begin{array}{l}\text { Paper/web/mobile } \\
\text { based Exam }\end{array}$ & 41.195 & 1.85 & 22.24 & 12.38 & 03 \\
\hline $\begin{array}{l}\text { Group * Pa- } \\
\text { per/web/mobile } \\
\text { based Exam }\end{array}$ & 7.890 & 1.85 & 4.23 & 2.39 & .103 \\
\hline Error & 119.700 & 66.7 & 1.78 & & \\
\hline Total & 311.213 & 113.4 & & & \\
\hline
\end{tabular}


TABLE IV. STUDENTS' PERCEPTIONS ON PAPER, WEB, AND MOBILE BASED EXAMS.

\begin{tabular}{|l|c|c|}
\hline \multicolumn{1}{|c|}{ Criteria } & $\bar{X}$ & S \\
\hline & 1.85 & 0.99 \\
\hline 1. I prefer the paper based Exam. & 4.65 & 0.59 \\
\hline 2. I liked the web based Exam. & 3.30 & 1.42 \\
\hline 3. I liked mobile based Exam. & 4.45 & 0.60 \\
\hline $\begin{array}{l}\text { 4. Use of different media, such as internet and } \\
\text { WAP increased my attention to the course. }\end{array}$ & 4.30 & 0.80 \\
\hline $\begin{array}{l}\text { 5. If I am to undertake Exam in other courses, I } \\
\text { would prefer web based Exam. }\end{array}$ & 3.15 & 1.31 \\
\hline $\begin{array}{l}\text { 6. If I am to undertake Exam in other courses, I } \\
\text { would prefer mobile based Exam }\end{array}$ & 3.70 & 1.30 \\
\hline 7. It was easy to use mobile based Exam. & 4.70 & 0.57 \\
\hline 8. It was easy to use web based Exam. & 1.90 & 1.12 \\
\hline $\begin{array}{l}\text { 9. Paper based Exam was the best in offering } \\
\text { feedback on my answers to the questions and my } \\
\text { scores. }\end{array}$ & 4.25 & 1.12 \\
\hline $\begin{array}{l}\text { 10. Web based Exam was the best in offering } \\
\text { feedback on my answers to the questions and my } \\
\text { scores. }\end{array}$ & 1.19 \\
\hline $\begin{array}{l}\text { 11. Mobile based Exam was the best in offering } \\
\text { feedback on my answers to the questions and my } \\
\text { scores. }\end{array}$ & 3.50 \\
\hline
\end{tabular}

\section{A. Anticipated Results and Evaluation Criteria}

- This research study used a mixed methods approaches which emphasized on qualitative data collection [10]. The project data is collected from the following specific resources:

i. Primary data will collect from the first prototype of "Questions-Bank" project that implemented in three Qatari schools, and presented in the IMCL'09 and ICL2009 international conferences. This includes the articles by Hosam F. El-Sofany, et al [6, 7], and the article by Samir A. El-Seoud et al [21].

ii. Qualitative data is collected from Alwakra School (as a performance site) through the project documents, system testing and implementation, scheduled interviews with involved project participants, and analysis of open (free-response) questions from two questionnaires. Moreover, we used external material such as books and research articles covering relevant topics for this study.

iii. Secondary data collected from the E-learning literature. A lot of research literature on E-learning in conjunction with school education is available; and relevant elements in relation to E-learning and customization for corporations are drawn out in this study. The search strategy included electronic databases and hand searches of some published books on E-learning. We used databases like ACM Digital Library, IEEE Xplore, ISI Web of Science and CiteSeerX. In addition, we used Google Scholar that provided a simple way to broadly search for scholarly literature across many disciplines and sources [12].

iv. Supplementary data is taken from the PSUT, as a collaborative academic institution in this study

The Quantitative Research Approach: Two electronic questionnaires are given to the students who follow the two classes (9-A and 9-B). These questionnaires are conducted primarily to get an indication of how the students perceived the overall quality in the courses. A mix between free-response questions, dichotomous questions, multiple-choice questions, checklists and rating questions were used. The instrument designs for these questionnaires are based on Cooper \& Schindler (chapters 12-13) [11]. The questionnaires are distributed to the students as part of the mandatory exercise program. All 30 students in the first group answered the first questionnaire and the other 30 students in the second group answered the second questionnaire. At the end of the semester the two groups are taken the final exam in three subjects (Mathematic, Science, and English language) using the project.

\section{B. Evaluation Criteria}

We have evaluated the system according to the following main criteria:

- Usability: Is the system providing a coherent and flexible user interface that can be used easily with all users? Has the system an obvious component which allows the user to navigate easily? Are the system applications easy to use by students, teachers, and parents? Is the system adaptive to user needs? Is the tracking component working properly and produce the expected results

- Supportability: Can the system be easily modified or extended easily? Can teachers and administrators add materials easily?

- Contents and Design: Are the design and contents of the system satisfactory to student, teachers and parents? What are their feedbacks? Does the system cover well the topics? Are they useful and meet their goals? Quality of texts, images, sounds, and clips? We compare the progress of students.

- Performance: Are the performance requirement concerned with quantifiable attributes of the system, such as response time, throughput availability and accuracy?

- Flexibility: Is the system flexible, since it will be used regularly with a new set of initial data and can accommodate changes in database such as modifying the contents?

- Security: Is the system preventing unauthorized users to access the system?

\section{REFERENCES}

[1] Hosam F. El-Sofany, Ahmad Hasna, Jihad Jaam, Fayed Ghaleb, and Samir A. El-Seoud, "A Web-Based E-Learning System Experiment". International Journal of Computing \& Information Sciences (IJCIS), Vol. 4, No. 1, P22-29, April 2006.

[2] Fayed F. M. Ghaleb, Sameh S. Daoud, Ahmad M. Hasna, Jihad M. Jaam, and Hosam F. El-Sofany, "A Web-Based E-Learning System Using Semantic Web Framework". Journal of Computer Science 2 (8): 619-626, 2006, ISSN 1549-3636. Science Publications U.S.A, 2006.

[3] Fayed Ghaleb, Sameh Daoud, Ahmad Hasna, Jihad Jaam, Samir A. El-Seoud, and Hosam El-Sofany, "E-Learning Model Based On Semantic Web Technology". International Journal of Computing \& Information Sciences (IJCIS), Vol. 4, No. 2, P63-71, August 2006.

[4] Hosam F. El-Sofany, and Samir A. El-Seoud, "Towards the Development of an M-Learning System: A New Stage to Enhance Higher Education", International Journal of Interactive Mobile Technologies (iJIM), Vol. 3, Issue 3 , Pages 1-6, doi:10.3991/ijim.v3i3.719, July 2009. 
[5] Samir Abou El-Seoud, Ashraf M.A. Ahmad and Hosam Farouk El-Sofany, "Mobile Learning Platform Connected to Moodle using J2ME", International Journal of Interactive Mobile Technologies (iJIM), Volume 3, Issue 2, P: 46-54, doi:10.3991/ijim.v3i2.751, April 2009.

[6] Hosam F. El-Sofany, Samir A. El-Seoud, F.F.M. Ghaleb, Shaima Ibrahim, and Noor Al-Jaidah, "Questions-Bank System to Enhance E-Learning in School Education", International Journal of Emerging Technologies in Learning - iJET, Volume 4, Issue 3, Pages 8-19, doi:10.3991/ijet.v4i3.978, September 2009.

[7] Hosam Farouk El-Sofany, Noor Al-Jaidah, Shaima Ibrahim, and Salha Al-kubaisi, "Web-based Questions-Bank System to Improve E-Learning Education in Qatari School", Journal of Computer Science 5(2): P: 79-108, 2009, ISSN 1549-3636, Science Publications U.S.A, March 2009.

[8] Berners-Lee, T. what the Semantic Web can represent. http://www.w3.org/DesignIssues /RDFnot.html, 2000.

[9] Nejdl, W. Learning Repositories - Technologies and Context. In Proc. of ED-MEDIA 2001 World Conference on Educational Multimedia, Hypermedia \& Tele-communications, 2001.

[10] Creswell, J. W.. Research Design: Qualitative, Quantitative, and Mixed Methods Approaches (second edition). Thousand Oaks, CA: Sage Publications, 2003.

[11] Cooper, D. R., \& Schindler, P. S. Business Research Methods ( $8^{\text {th }}$. edition). Boston, MA: Irwin McGraw-Hill, 2008.

[12] Google Scholar. Retrieved March 6, 2009 from the Google Scholar web site: http://scholar.google.com/intl/en/scholar about.html. 2009

[13] Mercier F, David B, Chalon R, Berthet, JP. Interactivity in a large class using wireless devices. Proceedings of Mlearn, Bracciano (Rome), Italy pp. 129-132, 2004.

[14] Kim CS. Work in progress - Mobile computer based classroom assessment. Proceedings of 35th ASEE/IEEE Frontiers in Education Conference, October 19 - 22, Indianapolis. Retrieved April 9 , 2008, from http://ieeexplore.ieee.org/iel5/10731/33854/01611 904.pdf?ar number=1611904, 2005.
[15] Rouet MM, Ney M, Charles S, Boidin GL. Students’ performance and satisfaction with Web vs. paper-based practice quizzes and lecture notes. Comput. Educ. 53: 375-384, 2009. doi:10.1016/ j.compedu.2009.02.013

[16] Seppälä P, Alamäki H. Mobile learning in teacher training. J. Comp. Assist. Learn. 19(3): 330-335, 2003. doi:10.1046/j.02664909.2003.00034.x

[17] Dawabi P, Wessner M, Neuhold E. Using mobile devices for the classroom of the future. Proceedings of Mlearn 2003 Conference on Learning with Mobile Devices, London pp. 14-15, 2003.

[18] Scornavacca E, Marshall S. TXT-2-LRN: Improving students' learning experience in the classroom through interactive SMS. Proceedings of the 40th Hawaii International Conference on System Sciences, Hawaii, 2007.

[19] Wentling L, Park J, Peiper C. Learning gains associated with annotation and communication software designed for large undergraduate classes. J. Comp. Assist. Learn. 23(1): 36-46, 2007. doi:10.1111/j.1365-2729.2007.00197.x

[20] Homan S, Wood K. Taming the mega-lecture: Wireless quizzing. Syllabus Magazine. October. Retrieved March 29, 2009, from http://www.syllabus.com/article. asp?id=8251, 2003.

[21] Samir Abou El-Seoud, Hosam Farouk El-Sofany, and Yahia AlHalabi, "Wireless Questions-Bank System to Enhance M-Learning in School Education". International Journal of Interactive Mobile Technologies (iJIM), Vol. 4, Issue 1, Pages 4-8, doi:10.3991/ijim.v4i1.1129, January 2010.

\section{AuTHORS}

Hosam F. El-Sofany is with the Cairo Higher Institute for Engineering, Computer Science, and Management, Cairo, Egypt.

Samir A. El-Seoud is with Technische Universität Darmstadt, Darmstadt, Germany

Submitted September 5th, 2010. Published as resubmitted by the authors December 11th, 2010 